\title{
A Study on the Use of Big Data in Computer Basic Teaching Reforms
}

\author{
Ding Jie ${ }^{1}$, Zhao Guotao ${ }^{2, \text { a }}$ \\ ${ }^{1}$ College of Technology, Hubei Engineering University, Xiaogan, 432000, China \\ 2 Hubei Engineering University, Xiaogan, 432000, China \\ azgt2344800@163.com
}

Keywords: internet; computer basics; teaching;

\begin{abstract}
Nowadays, Internet online course teaching is a popular educational method in all major universities. Building a massive network course reservoir is the focus of curriculum construction in which, introducing the Bid Data technology to follow and analyze students' learning paths can find out specific areas accessed most by certain student groups. Based on such findings, we can target those areas for in-depth resource excavation, therefore, greatly improve the efficiency of the building up of cyber teaching resources, letting basic computer teaching dock internet learning seamlessly, and integrating internet technology into college basic computer teaching reform while at the same time enhancing students' initiativeness in their self-directed learning.
\end{abstract}

\section{Introduction}

The virtually infinite multimedia teaching resources are a powerful complement for classroom lectures; it can fully demonstrate the academic strength of a certain discipline. By introducing Big Data technology into teaching resources construction, we can change the originally static materials into interactive learning platforms and provide individualized instructive service according to the needs and habits of different students' learning habits from different colleges and departments[1]. Such interaction between internet teaching and students' independent learning aided by Bid Data will allow all kinds of educational resources to provide students with more effective service, making them more active in self learning.

Currently Big Data is a hot topic. The main purpose of using Big Data technology is to sharpen our observation and strengthen our decision making ability by re-analyzing and re-digging in existing data resources in order to find out their interrelations and commonalities, therefore to improve our working efficiency[2]. Right now, the most outstanding evidence of wide spread Big Data use in our high educational system is the introduction of public network learning platforms such as the popular "Qixue Online Classroom", "Netease Open Class", "School online Public Education Network Platform, as well as the alignment of the MOOC system with the UOOC system[3]. These platforms are developed on existing excellent courses with the introduction of Big Data technology. The use of Big Data can personalize or humanize students' learning process so that they can study freely according to their personal needs for rapid growth and progress by breaking the restrictions of time, space and locations.

\section{Problems facing the construction of college computer network resources reservoir}

All high educational institutions have their own computer network teaching resource reservoirs based on their own specific needs. But when teachers construct their individual course data base, they sometimes use different file formats, materials and standards for the same course[4]. For example, some use Screen Video Expert to make EXE executable files; while some use the PLV format; and still others use MP4 and AVI etc. this can cause a problem of incompatibility for students' internet learning. So in order to guarantee later resources' compatibility, here we have an issue of standardizing our resource construction format according to the standard of excellent 
courses and MOOC net teaching resources construction.

Today, computer basic course has become a compulsory subject in all colleges and universities, but each teacher has his own teaching style and characteristic, so when preparing their own teaching materials, different teachers may have different emphases on certain aspects, especially when they choose instance analysis. As a result, the net resources can sometimes be quite chaotic-some materials are relevant to the existing technology and some materials are obtained on the internet with upgraded versions, and some are quite repetitive, which may fail to provide students' with specific service to reinforce their basic knowledge points[5].

Many universities, due to the lack of administrative personnel, use FTP and other public platforms to share net learning resources. This is convenient for giving assignments, but students sometimes can delete some materials by mistake, causing unnecessary disruption to their net learning[6]. So in order to get students focused on net learning and assignment submission so as to improve teaching efficiency, it is necessary for us to increase our efforts on strengthening net learning management and maintenance.

\section{Advantages of internet Big Data technology in the construction network resources}

The quality of basic computer courses cyber source, can be evaluated according to the amount of student visits; based on such information, network learning platforms can use Big Data technology to conduct data analysis and source excavation, so as to draft relevant trajectories of source application for students from different classes and departments. Since the data are up to date, we can repeatedly re-explore the most frequently used materials and renew the most visited courses with the latest information in order to improve students' initiativeness and interests.

By analyzing students' learning habits and interests, Big Data can use its artificial intelligence to recommend relevant knowledge points for the resources that are mostly used by students. Once a student opens a certain platform, a window will pop up, offering the student Big Data processed resources based on the material which has been used by him in his previous visits. After all, cyber resources are infinite, Big Data can feed back the most relevant material to each individual student according to his needs[7]. This can greatly shorten the amount of time students used to spend in searching without the help of Big Data technology. At the same time, Big Data can make study plans for individual students according to their learning habits. In one word, by increasing exchanges between students and computers, we can rapidly improve students study efficiency.

The biggest characteristic of Big Data is its ability to re-excavate and classify the data at the same time. The most important data on the computer basic course cyber learning platforms are the ones on students learning status and learning paths. Commonly used platforms only record such information as when they study, what resources they visit, how they do self tests and when they have $\mathrm{Q}$ and A exchange with computers. Such information seems quite ordinary, but if it is processed with Big Data technology, we can obtain certain rules of how students do their self-directed learning. Big Data is there searching for rules. With the rules, we can improve students learning environment. According to the data provided by the learning platforms, Big Data can classify and grade students' achievements[8]. And with such Big Data feedbacks, teachers can offer students timely and targeted tutoring. Since the feedbacks are always up to date, it can be a powerful complement for classroom teaching. So the introduction of Big Data technology into network learning platforms can optimize teaching effects.

\section{Application of college computer basic net resources reservoir against the background of Big Data technology}

\section{Building net teaching platforms based on Big Data technology}

By now, the construction of college network learning platforms has become mature. Such platforms are mainly used to classify and store network learning resources so as to provide learners with the convenience of visiting and studying. These traditional learning platforms are apparently dull and outmoded in today's Big Data age[9]. With Big Data technology we can revitalize the previously monotonous learning platforms, making them capable of thinking, more intelligent, and 
enable students to interact with them and even let platforms know specific areas in which students' are most interested. Further more, Big Data can make learning plans for different students according to their individual needs. Such active interaction, can then give teachers feedbacks about students' learning situation, and then give targeted tutoring which will make students feel that their teachers' guidance is just what they need most. Therefore, Big Data will make the relationship between teachers and students more close[10]. Good teacher-student relationship is conducive to strengthen students' proficiency in their study, making them more motivated, more demanding for knowledge, and resulting in the maximum application of net learning platforms.

\section{Optimizing course resources construction with Big Data technology}

Big Data can draw a flow diagram of resource visiting spots by studying students' learning status on learning platforms. With the visiting flow diagram, we can make targeted net resources construction, concentrating on the most visited knowledge points for refining dissection and renewing resources[11]. This can serve as guidance for teachers' teaching activities and selecting teaching materials. In the past, such work is done by the teachers alone based on their own understanding of the subjects they teach. Now with Big Data, the focus has turned to students. What resources that students needs most, we can increase the building up in those data. After all, students are the masters in learning; education is to provide service for students[12]. Big Data can realize the ideal of thinking of what students think of. So during resources reservoir construction, we must put more emphasis on the resources students need most. In this way, we can make the construction of net learning resources reservoir more systematic and consummate

\section{Using large data technology to track students' learning hot spot}

In computer based network learning, each student, according to his own interest and personality in accessing network learning resources has his own learning path which can reflect the learning characteristics and learning habits of the student. Big data can timely monitor students learning status along their learning paths, and predetermine their next paths. Such a calculating technology can turn net learning platforms into real time tutors for students. The intelligentized learning platforms will enable students to have interactions with computers. Meanwhile, teachers can have a clear knowledge of students' latest learning trend based on the data of students' learning paths. This can make classroom teaching more clearly targeted. Bid Data technology can make the learning platforms capable of thinking. So the path monitoring method can increase interactivity between computers and humans, leading students into a world of comprehensive, tree-dimensional learning.

\section{Setting up a diversified and scientific evaluation mechanism}

The purpose of network learning is to improve students' self-learning ability, making passive learning active. And so the evaluation system of network learning must be student oriented, scientifically, multilaterally arrange the amount of time for students' net learning, so as to guarantee that they are really involved in and benefited from such effective self learning. The evaluation mechanism can combine the information provided by Big Data's analysis on students' net learning and tests with the results of teachers' classroom exchanges with students, such as Q and A, chapter exams, and students' submission of assignments and experimental works, to conduct a comprehensive assessment[13]. And the final conclusion of students' achievements should even take into consideration of adjustment for different disciplines in order to achieve the designed result.

\section{Conclusion}

Internet big data technology application is the inevitable trend of the current social development. Up to now, it has gradually integrated into every aspect of our society. Introducing the concept of big data in higher education is bound to bring the reform of higher education to a new height. The use of big data technology concept in computer basic course in the cyber source construction will make university autonomous learning intelligent, change students' role in higher education from passive learners to active ones, adapt the reforms of university computer basic curriculum to contemporary social development, and ultimately improve the teaching quality of basic computer courses. 


\section{Acknowledgements}

This work was financially supported by Teaching research project of College of Technology of Hubei Engineering University (2017JY06) ,the Science and Technology Research Project of Education Department of Hubei Province (B2017501).

\section{Reference}

[1]Dai Zhenhua, The Application of MOOC and Big Data Technology in the University Computer Foundation Teaching[J]. Computer \& Telecommunication, 2014(6):41-43

[2]Jin Limo. Application of big data technology in colleges and universities education[J]. Wireless Internet Technology, 2017(18):136-137

[3]Li Qi, LI Ying, ZHAO Xiuli. A blending teaching mode for computer courses based on MOOC platform [J]. Computer Engineering \& Science,2014(12):111-113

[4]ZHAO Jungian, HU Zhen Bo. Research on the Informative Teaching Mode of University under the Environment of Big Data[J], Information Science,2016(1):92-95

[5]Lane, J. E. Building a Smarter Universtiy: Big Data, Innovation and Analytics [M].New York: State University of New York Press, 2014.

[6]Hershkovitz, A. Nachmias, S. Online Persistence in Higher-education Web-supported Courses [J].The Internet and Higher-education, 2011, 14(2):98-106.

[7]Gan Ronghui, He Gaoda. Value Orientation and Implementation Path of Higher Education Reform in Big Data Era[J], China Educational Technology,2015(11):70-76

[8] DAVIS K S. “Change is hard”: what science teachers are telling us about reform and teacher learning of innovative practices[J].Science education,2003(87):3-30

[9] JACKSON P. The practice of teaching[M]. New York: Teacher College Press, 1986

[10]WANG Lu, LI Yao. Research on Teaching Phenomena Based on Big Data of Classroom Teaching Behavior[J], e-Education Research,2017(4):77-85

[11]Ying Pei, Fu Shiqiu, Wu Feng. Visualization analysis of hot topics in big educational data research and existing problems[J]. Distance Education in China,2017(12):46-53

[12]JACOBS A.The Pathologies of Big Data[J].Com-munications of the Association for Computin g Ma-chinery,2009(8):36-44.

[13]FISHER D.DELINE R.CZERWINSKI M,DRUCK-ER S.Interactions with Big Data Analytics[ J].Inter-actions,2012(5-6):50-59. 